Case Reports in
Gastroenterology
Case Rep Gastroenterol 2020;14:426-435

DOI: 10.1159/000508413

Published online: August 26, 2020

(C) 2020 The Author(s)

Published by S. Karger AG, Basel www.karger.com/crg

This article is licensed under the Creative Commons Attribution-NonCommercial 4.0 International License (CC BY-NC) (http://www.karger.com/Services/OpenAccessLicense) Usage and distribution for commercial purposes requires written permission.

\title{
Alpha-Fetoprotein-Producing Early Gastric Cancer with Intramucosal Hepatoid and Fetal Enteric Differentiation
}

\author{
Mai Iwaya ${ }^{a, b} \quad$ Robert Riddell $^{b} \quad K^{\prime}$ Koji Asano ${ }^{c} \quad K^{2} a z u o$ Kobayashid \\ Takeshi Uehara $^{\mathrm{a}}$ Hiroyoshi Ota ${ }^{\mathrm{e}}$
}

aDepartment of Laboratory Medicine, Shinshu University Hospital, Matsumoto, Japan; ${ }^{b}$ Department of Pathology and Laboratory Medicine, Mount Sinai Hospital, University of Toronto, Toronto, ON, Canada; 'Department of Pathology, Suwa Central Hospital, Chino, Japan; dDepartment of Gastroenterology, Kobayashi Hospital, Nagano, Japan; eDepartment of Clinical Laboratory Sciences, School of Health Sciences, Shinshu University, Matsumoto, Japan

\section{Keywords}

Alpha-fetoprotein-producing gastric cancer · Hepatoid adenocarcinoma - Early gastric cancer · SALL4

\begin{abstract}
Alpha-fetoprotein (AFP)-producing gastric carcinomas (AFPGCS) are relatively rare tumors known to have a poor prognosis and commonly found as advanced lesions. Histologically, AFPGCs have been described as having hepatoid and fetal enteric (enteroblastic) morphology and are associated with conventional adenocarcinomas. Prior studies reported a hepatoid component present only in invasive areas and hypothesized that AFPGCs may develop hepatoid features during the process of tumor invasion. We report three cases of AFP-producing early gastric cancer which had an intramucosal hepatoid component. Immunohisto-
\end{abstract}




\section{Case Reports in Gastroenterology}

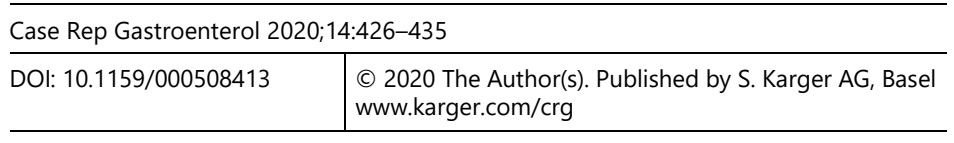

Iwaya et al.: Early Gastric Cancer with Intramucosal Hepatoid Morphology

chemistry showed that the hepatoid component was diffusely immunoreactive for SALL4, AFP, arginase-1, and HepPar1, and focally for CDX2 and PDX1. An intramucosal transition between the hepatoid component and conventional intramucosal adenocarcinoma was identified. Two patients also had a coexistent fetal enteric component, which was admixed with a hepatoid component. Although at an early stage one patient subsequently developed liver metastasis and a second patient was suspected of having liver metastasis, these were not biopsy-proven. The latter patient had a previous history of hepatocellular carcinoma (HCC) and SALL4 was used on the $\mathrm{HCC}$ to distinguish metastatic/further HCC from a gastric metastatic primary with hepatoid differentiation.

(C) 2020 The Author(s) Published by S. Karger AG, Basel

\section{Introduction}

Extrahepatic alpha-fetoprotein (AFP)-producing carcinomas are relatively rare tumors and have been reported in various organs such as stomach, lung, gallbladder, ovary, colon, ampulla of Vater, and pancreas [1-5]. The stomach is one of the more common sites for these cancers and typically they are found as advanced lesions and have a high incidence of liver metastasis and a poor prognosis [6, 7]. Histologically, AFP-producing gastric carcinomas (AFPGCs) have also been described as having both hepatoid and fetal enteric (enteroblastic) morphology and concurrent conventional adenocarcinoma [8-12], which is most frequently of the intestinal type [8]. Prior studies reported that a hepatoid component is only present in invasive areas and suggested that AFPGCs might acquire hepatoid differentiation and AFPproducing ability during the process of tumor invasion $[8,13]$. Here, we report three patients with AFP-producing early gastric cancer (GC) having an intramucosal hepatoid and additional fetal enteric components.

One patient had a previous history of hepatocellular carcinoma (HCC) in which SALL4 was not immunoreactive, suggesting that this was not the source of the metastatic disease. To the best of our knowledge, these are the first reported cases of early GC with an intramucosal hepatoid and additional enteroblastic components.

\section{Patients and Methods}

\section{Case 1}

A 72-year-old male was found to have an early incidental GC during an annual health examination. He had undergone a partial hepatectomy for HCC 7 years before. Serum AFP level was slightly elevated $(14.9 \mathrm{ng} / \mathrm{mL}$ ), serum carcinoembryonic antigen (CEA) and carbohydrate antigen 19-9 (CA19-9) levels were within the normal range. The patient underwent distal gastrectomy, and 3 years after the surgery multiple liver lesions had developed, but no liver biopsies were performed. The patient died of disease 77 months after the gastric surgery.

Case 2

A 77-year-old male was found to have an early GC during a periodic health examination that included endoscopy. His past medical history was unremarkable except for an aortic 


\section{Case Reports in Gastroenterology}

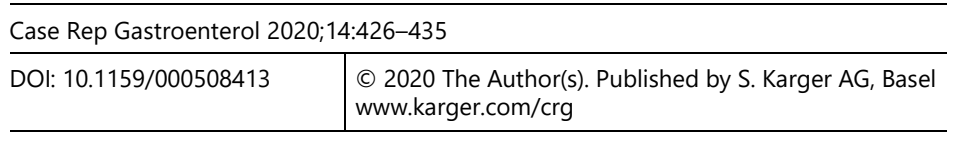

Iwaya et al.: Early Gastric Cancer with Intramucosal Hepatoid Morphology

aneurysm and a skull fracture. Serum CEA and CA19-9 levels were within normal range. Serum AFP level was not evaluated. Distal gastrectomy was performed, and 48 months after the surgery the tumor recurred as liver metastasis. Serum AFP level was markedly elevated $(119,190 \mathrm{ng} / \mathrm{mL})$. After undergoing chemotherapy, the serum AFP level was reduced to within the normal range and no obvious liver lesions were detected on computed tomography scan. Amazingly, 106 months after the surgery, the patient is alive and well with no recurrence.

\section{Case 3}

A 66-year-old female who had had a distal gastrectomy for early GC 23 years before was found to have an additional early GC during a routine health checkup that included endoscopy. Serum CEA and CA19-9 levels were within normal range, but serum AFP level was not measured. The patient underwent total residual gastrectomy. No symptoms or abnormal findings suggesting recurrence have been detected in the 60 months since her surgery.

\section{Immunohistochemistry and Staining Evaluation}

The tissue specimens were fixed in $10 \%$ buffered formalin, embedded in paraffin serial tissue sections (thickness $3 \mu \mathrm{m}$ ) were prepared from paraffin blocks and stained with H\&E for histological examination or used for immunohistochemical staining. Immunohistochemical staining was performed using the following primary antibodies in accordance with the manufacturer's instructions: SALL4 (clone: 6E3; Anova, Taipei City, Taiwan), AFP (A0008; Agilent, Santa Clara, CA, USA), arginase-1 (HPA003595; Atlas Antibodies AB, Bromma, Sweden), HepPar1 (OCH1E5; Agilent), CDX2 (CDX2-88; BioGenex, San Ramon, CA, USA), PDX1 (guinea pig polyclonal antibody; generously provided by Prof. Christopher V.E. Wright, Vanderbilt University Medical School, Nashville, TN, USA), MUC2 (Ccp58; Novocastra, Newcastle upon Tyne, UK), MUC5AC (CLH2; Novocastra), and MUC6 (CLH5; Novocastra). MUC2, MUC5AC, and MUC6 specifically expressed in goblet cells of the intestine, in the gastric foveolar mucous cells, and in the gastric gland mucous cells, respectively. In well-developed gastrointestinal tract, PDX1 is expressed in gastric antrum and duodenum with decreased expression in the distal small intestine $[14,15]$.

The results of immunostaining were evaluated as the percentage of positively stained cells. The degree of positive staining was graded into four categories as follows: (i) 0 , negative, no positive cells; (ii) +, focal expression, less than one-third of cells were positive; (iii) ++ , onethird to two-thirds were positive; and (iv) +++ , diffuse expression, more than two-thirds of the cells were positive.

\section{Results}

In case 1 , a polypoid solid lesion measuring $15 \times 15 \mathrm{~mm}$ was detected in the distal third of the stomach. While there was no submucosal invasion, lymphovascular invasion was identified in the submucosa (Fig. 1). The lesion was composed of tumor cells with abundant eosinophilic cytoplasm, centrally located vesicular nucleus, and prominent nucleolus arranged in trabecular or solid nests with a sinusoidal arrangement of vascular channels. The features were those of hepatoid carcinoma. The tumor cells were diffusely immunoreactive for arginase-1, HepPar1, and SALL4, moderately for AFP, and focally for PDX1 and CDX2 (Fig. 2). A 


\section{Case Reports in Gastroenterology}

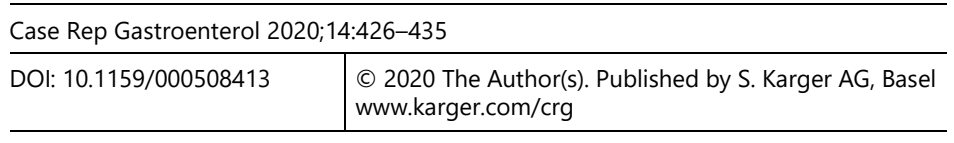

Iwaya et al.: Early Gastric Cancer with Intramucosal Hepatoid Morphology

small portion of conventional intramucosal adenocarcinoma was also present. An intramucosal transition from conventional type to hepatoid component was identified (Fig. 2). The conventional component showed a gastric-type immunoprofile (MUC5AC+, MUC6+, CDX2-, MUC2-) and was diffusely immunoreactive for PDX1. Given the previous history of HCC in case 1, SALL4 immunohistochemistry was performed for the resected HCC specimen and no SALL4 expression was seen.

In case 2, a $16 \times 8 \mathrm{~mm}$ depressed lesion was found in the lower third of the stomach. Microscopically, tumor invaded into the superficial submucosa, and dysplastic mucosal glands which had clear cytoplasm resembling fetal gut were seen (fetal enteric/enteroblastic component). This component was diffusely immunoreactive for SALL4, AFP, PDX1, and CDX2, and patchily for MUC2 and HepPar1 (Fig. 3). Both an intramucosal hepatoid component and conventional component were present, the hepatoid component showing the same immunoprofile as in case 1 (Fig. 3). In the submucosa as well as the hepatoid and fetal enteric components were admixed and difficult to clearly distinguish. The hepatoid component focally showed arginase-1 positivity. The conventional component showed an intestinal predominate immunophenotype (CDX2+++, MUC2+, MUC5AC+, MUC6+) and was focally immunoreactive for SALL4 (Fig. 3).

In case 3 , a $15 \times 10 \mathrm{~mm}$ slightly depressed lesion was detected in the upper third of the residual stomach. The tumor invaded the submucosa and intramucosal hepatoid, and fetal enteric and conventional components were identified (Fig. 4).

The immunohistochemical profiles observed in these three cases are summarized in Table 1.

\section{Discussion}

Here, we report three cases of early GC with an intramucosal hepatoid component, suggesting that this component can evolve very early in the development of these tumors even in the lamina propria. Nevertheless, there was still an intramucosal transition between conventional-type component and hepatoid component, suggesting that "de novo" hepatoid carcinomas do not always require a conventional invasive component, even intramucosal, to initiate those patterns of differentiation.

Because of the history of partial hepatectomy for HCC in case 1, SALL4 immunohistochemistry was performed on the resected HCC, but no SALL4 expression was identified. SALL4 is an embryonic stem cell marker and a transcription factor playing an important role in maintaining self-renewal [16-18]. It is diffusely expressed in both the hepatoid and fetal enteric components, but can also be expressed focally in conventional adenocarcinoma. Ushiku et al. [13] reported that SALL4 is diffusely expressed in fetal gastric epithelium and AFPGCs, whereas SALL4 expression is not identified in HCC. Although other studies reported SALL4 expression in HCC, diffuse expression is relatively rare $[19,20]$. Based on the differential expression of SALL4 and the presence of an intramucosal transition with the conventional component, the gastric lesion and HCC were considered as separate primary cancers. After gastrectomy, multiple liver lesions were clinically diagnosed as recurrent HCC; however, some radiological studies reported that liver metastasis from hepatoid adenocarcinoma of the stomach shared many imaging similarities with HCC [21, 22]. Although the gastric lesion was 


\section{Case Reports in Gastroenterology}

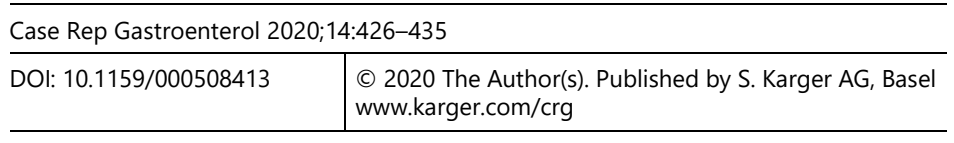

Iwaya et al.: Early Gastric Cancer with Intramucosal Hepatoid Morphology

limited to the lamina propria, submucosal lymphovascular invasion was identified. In this patient, liver metastases from AFPGCs were thought to be the most likely explanation. SALL4 is a useful biomarker to distinguish primary gastric hepatoid and enteroblastic adenocarcinoma from HCC.

While all three AFPGCs were early stage at resection (pT1N0M0), one case developed liver metastasis after gastrectomy (case 2) and case 1 had had liver metastases as well, but these were not biopsied.

AFPGC has a higher intrinsic malignant potential than conventional GC in pT1 stage [23]. The present cases also indicate high potential for metastases even at an early (intramucosal) stage. Vigilant clinical follow-up (imaging and serology) should be considered for AFPGCs.

The hepatoid component showed diffuse arginase- 1 and HepPar1 expression. Arginase1 , a binuclear manganese metalloenzyme that catalyzes the hydrolysis of arginine to ornithine and urea, is specifically expressed in normal hepatocytes and HCCs [24]. Although HepPar1 has been used to identify hepatoid differentiation, it recognizes the urea cycle enzyme carbamoyl phosphate synthetase 1 , which is present in small intestinal epithelial cells as well as in hepatocytes, so its expression is expected whenever there is intestinal differentiation [25]. HepPar1 has been reported to react with Barrett esophagus, gastric intestinal metaplasia, and adenocarcinomas of stomach and small intestine [26-28]. In our cases 2 and 3, the conventional component showed CDX2 expression which also suggests intestinal differentiation as well as HepPar1 expression; however no arginase-1 expression was identified. The features are interpreted as intestinal-phenotype adenocarcinoma and suggest that arginase- 1 is a more sensitive biomarker for hepatic differentiation than HepPar1.

In the present cases, the tumor showed hepatoid and fetal enteric differentiation. Embryologically stomach, proximal duodenum, and liver are derived from fetal foregut. The liver bud arises as an outpouching of the lumen of the distal foregut. In the present cases, the hepatoid component showed focal CDX2 and PDX1 expression. CDX2 is one of the homeobox genes which encodes an intestinal-specific transcription factor, expressed throughout the intestine, from duodenum to rectum [29]. Pancreatic-duodenal homeobox 1 gene (PDX1) is one of the transcription factors from the homeodomain gene family which regulates the development of the pancreas, duodenum, and gastric antrum [14]. Interestingly, during the early phase of embryogenesis in mice, both CDX2 and PDX1 show restricted expressed in the same region of liver and pancreas bud, and the same as Hlxb9 (Hb9), Hnf4a, Nkx2-2, Onecut1, Prox1, and Sox2 [30]. These findings suggest that the hepatoid component may share characteristics with the liver and pancreas buds.

In conclusion, we first demonstrated intramucosal hepatoid adenocarcinoma in three patients with AFP-producing early gastric hepatoid and fetal enteric adenocarcinoma, and that these lines of differentiation can evolve early in tumor development. The hepatoid and fetal enteric components may evolve very early on from conventional GC, and even when still intramucosal.

\section{Statement of Ethics}

Study approval was obtained from the Research Ethics Board at Shinshu University. Consent for publication was obtained from the patients and/or their families. 


\section{Case Reports in Gastroenterology}

Case Rep Gastroenterol 2020;14:426-435 (c) 2020 The Author(s). Published by S. Karger AG, Basel www.karger.com/crg

Iwaya et al.: Early Gastric Cancer with Intramucosal Hepatoid Morphology

\section{Conflict of Interest Statement}

All authors declare that they have no conflicts of interest related to this study.

\section{Funding Sources}

This research did not receive any specific grant from funding agencies in the public, commercial, or not-for-profit sectors.

\section{Author Contributions}

M. Iwaya mainly executed the project and wrote most of the manuscript. K. Asano and K. Kobayashi provided clinical data. H. Ota and T. Uehara contributed to the diagnostic process. R. Riddell was involved in the diagnostic process and suggested the property of the manuscript.

\section{References}

1 Bourreille J, Metayer P, Sauger F, Matray F, Fondimare A. Existence of alpha feto protein during gastricorigin secondary cancer of the liver. Presse Med. 1970 Jun;78(28):1277-8. French.

2 Cappetta A, Bergamo F, Mescoli C, Lonardi S, Rugge M, Zagonel V. Hepatoid adenocarcinoma of the colon: what should we target? Pathol Oncol Res. 2012 Jan;18(1):93-6.

3 Gardiner GW, Lajoie G, Keith R. Hepatoid adenocarcinoma of the papilla of Vater. Histopathology. 1992 Jun;20(6):541-4.

4 Hameed O, Xu H, Saddeghi S, Maluf H. Hepatoid carcinoma of the pancreas: a case report and literature review of a heterogeneous group of tumors. Am J Surg Pathol. 2007 Jan;31(1):146-52.

5 Mokrim M, Belbaraka R, Allaoui M, Kairaouani M, Mahassini N, Tahri A, et al. Hepatoid adenocarcinoma of the lung: a case report and literature review. J Gastrointest Cancer. 2012 Sep;43(Suppl 1):S125-7.

6 Adachi Y, Tsuchihashi J, Shiraishi N, Yasuda K, Etoh T, Kitano S. AFP-producing gastric carcinoma: multivariate analysis of prognostic factors in 270 patients. Oncology. 2003;65(2):95-101.

7 He R, Yang Q, Dong X, Wang Y, Zhang W, Shen L, et al. Clinicopathologic and prognostic characteristics of alpha-fetoprotein-producing gastric cancer. Oncotarget. 2017 Apr;8(14):23817-30.

8 Kinjo T, Taniguchi H, Kushima R, Sekine S, Oda I, Saka M, et al. Histologic and immunohistochemical analyses of $\alpha$-fetoprotein-producing cancer of the stomach. Am J Surg Pathol. 2012 Jan;36(1):56-65.

9 Uefuji K, Ichikura T, Tamakuma S. Roles of histological findings and serum AFP levels in the prognosis of AFP-producing gastric cancers. Jpn J Clin Oncol. 1994 Jun;24(3):135-40.

10 Ooi A, Nakanishi I, Sakamoto N, Tsukada Y, Takahashi Y, Minamoto T, et al. Alpha-fetoprotein (AFP)producing gastric carcinoma. Is it hepatoid differentiation? Cancer. 1990 Apr;65(8):1741-7.

11 Kodama T, Kameya T, Hirota T, Shimosato Y, Ohkura H, Mukojima T, et al. Production of alpha-fetoprotein, normal serum proteins, and human chorionic gonadotropin in stomach cancer: histologic and immunohistochemical analyses of 35 cases. Cancer. 1981 Oct;48(7):1647-55.

12 Matsunou H, Konishi F, Jalal RE, Yamamichi N, Mukawa A. Alpha-fetoprotein-producing gastric carcinoma with enteroblastic differentiation. Cancer. 1994 Feb;73(3):534-40.

13 Ushiku T, Shinozaki A, Shibahara J, Iwasaki Y, Tateishi Y, Funata N, et al. SALL4 represents fetal gut differentiation of gastric cancer, and is diagnostically useful in distinguishing hepatoid gastric carcinoma from hepatocellular carcinoma. Am J Surg Pathol. 2010 Apr;34(4):533-40.

14 Larsson LI, Madsen OD, Serup P, Jonsson J, Edlund H. Pancreatic-duodenal homeobox 1 - role in gastric endocrine patterning. Mech Dev. 1996 Dec;60(2):175-84. 


\section{Case Reports in Gastroenterology}

\begin{tabular}{l|l}
\hline DOI: 10.1159/000508413 & $\begin{array}{l}\text { ( } 2020 \text { The Author(s). Published by S. Karger AG, Basel } \\
\text { www.karger.com/crg }\end{array}$
\end{tabular}

Iwaya et al.: Early Gastric Cancer with Intramucosal Hepatoid Morphology

15 Sakai H, Eishi Y, Li XL, Akiyama Y, Miyake S, Takizawa T, et al. PDX1 homeobox protein expression in pseudopyloric glands and gastric carcinomas. Gut. 2004 Mar;53(3):323-30.

16 Wu Q, Chen X, Zhang J, Loh YH, Low TY, Zhang W, et al. Sall4 interacts with Nanog and co-occupies Nanog genomic sites in embryonic stem cells. J Biol Chem. 2006 Aug;281(34):24090-4.

17 Rao S, Zhen S, Roumiantsev S, McDonald LT, Yuan GC, Orkin SH. Differential roles of Sall4 isoforms in embryonic stem cell pluripotency. Mol Cell Biol. 2010 Nov;30(22):5364-80.

18 Yang J, Gao C, Chai L, Ma Y. A novel SALL4/OCT4 transcriptional feedback network for pluripotency of embryonic stem cells. PLoS One. 2010 May;5(5):e10766.

19 Shibahara J, Ando S, Hayashi A, Sakamoto Y, Hesegawa K, Kokudo N, et al. Clinicopathologic characteristics of SALL4-immunopositive hepatocellular carcinoma. Springerplus. 2014 Dec;3(1):721.

20 Yong KJ, Gao C, Lim JS, Yan B, Yang H, Dimitrov T, et al. Oncofetal gene SALL4 in aggressive hepatocellular carcinoma. N Engl J Med. 2013 Jun;368(24):2266-76.

21 Lin YY, Chen CM, Huang YH, Lin CY, Chu SY, Hsu MY, et al. Liver metastasis from hepatoid adenocarcinoma of the stomach mimicking hepatocellular carcinoma: dynamic computed tomography findings. World J Gastroenterol. 2015 Dec;21(48):13524-31.

22 Chang MY, Kim HJ, Park SH, Kim H, Choi DK, Lim JS, et al. CT features of hepatic metastases from hepatoid adenocarcinoma. Abdom Radiol (NY). 2017 Oct;42(10):2402-9.

23 Matsumoto K, Ueyama H, Matsumoto K, Akazawa Y, Komori H, Takeda T, et al. Clinicopathological features of alpha-fetoprotein producing early gastric cancer with enteroblastic differentiation. World J Gastroenterol. 2016 Sep;22(36):8203-10.

24 Yan BC, Gong C, Song J, Krausz T, Tretiakova M, Hyjek E, et al. Arginase-1: a new immunohistochemical marker of hepatocytes and hepatocellular neoplasms. Am J Surg Pathol. 2010 Aug;34(8):1147-54.

25 Butler SL, Dong H, Cardona D, Jia M, Zheng R, Zhu H, et al. The antigen for Hep Par 1 antibody is the urea cycle enzyme carbamoyl phosphate synthetase 1. Lab Invest. 2008 Jan;88(1):78-88.

26 Chu PG, Jiang Z, Weiss LM. Hepatocyte antigen as a marker of intestinal metaplasia. Am J Surg Pathol. 2003 Jul;27(7):952-9.

27 Kakar S, Muir T, Murphy LM, Lloyd RV, Burgart LJ. Immunoreactivity of Hep Par 1 in hepatic and extrahepatic tumors and its correlation with albumin in situ hybridization in hepatocellular carcinoma. Am J Clin Pathol. 2003 Mar;119(3):361-6.

28 Lagana S, Hsiao S, Bao F, Sepulveda A, Moreira R, Lefkowitch J, et al. HepPar-1 and Arginase-1 Immunohistochemistry in Adenocarcinoma of the Small Intestine and Ampullary Region. Arch Pathol Lab Med. 2015 Jun;139(6):791-5.

29 Werling RW, Yaziji H, Bacchi CE, Gown AM. CDX2, a highly sensitive and specific marker of adenocarcinomas of intestinal origin: an immunohistochemical survey of 476 primary and metastatic carcinomas. Am J Surg Pathol. 2003 Mar;27(3):303-10.

30 Sherwood RI, Chen TY, Melton DA. Transcriptional dynamics of endodermal organ formation. Dev Dyn. 2009 Jan;238(1):29-42. 


\section{Case Reports in Gastroenterology}

Case Rep Gastroenterol 2020;14:426-435

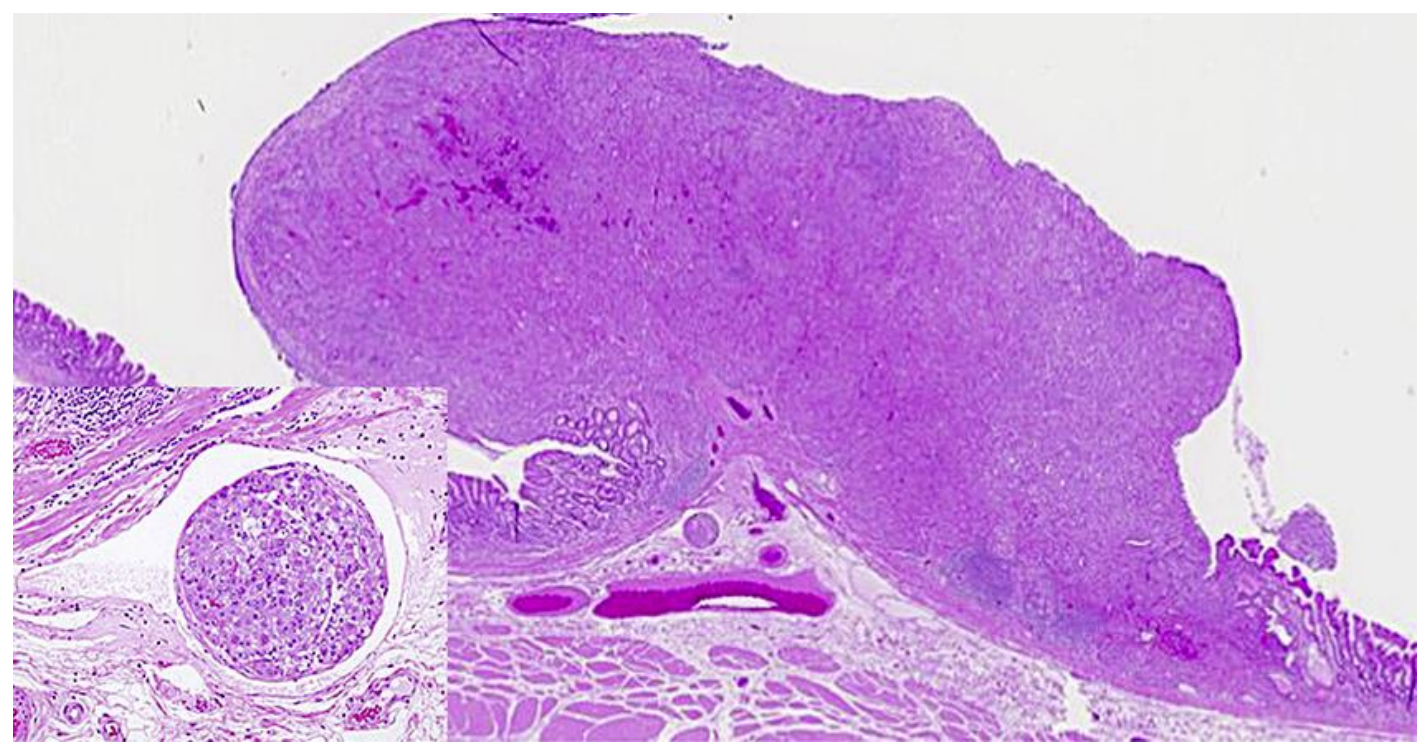

Fig. 1. Case 1 showed a polypoid solid intramucosal lesion. Submucosal lymphovascular invasion is present $(\times 5.7)$.
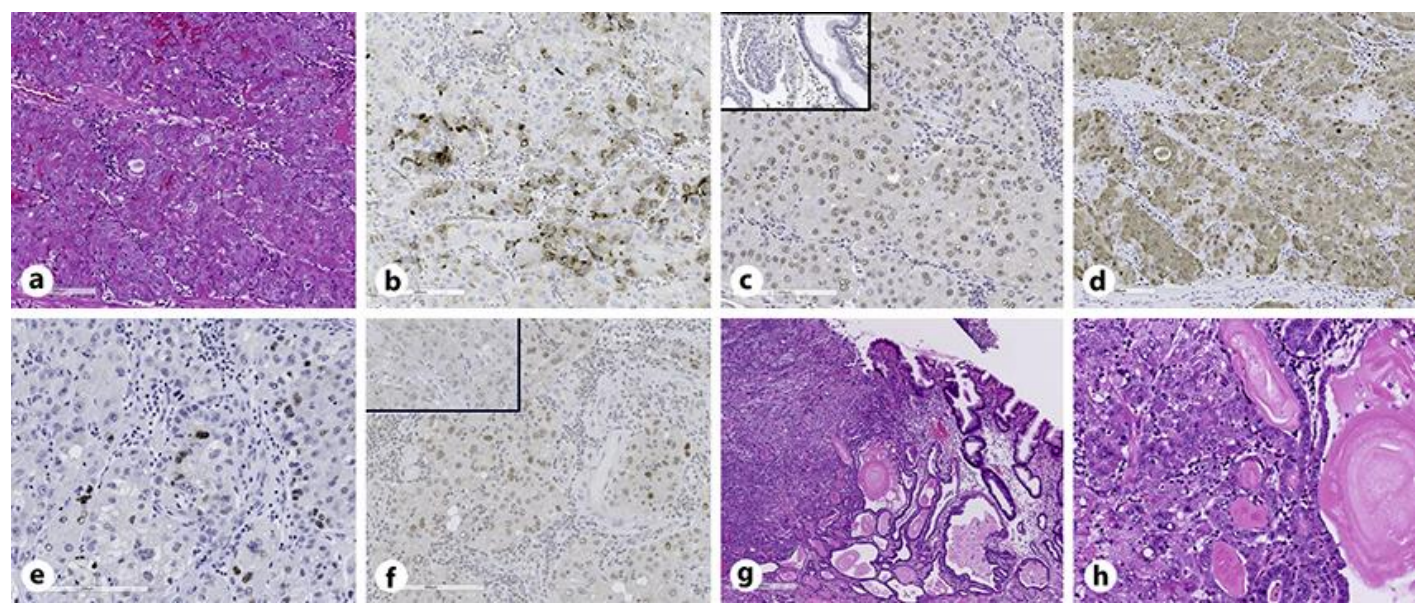

Fig. 2. Detail of case 1. The tumor showed intramucosal hepatoid appearance (a), tumor cells were immunoreactive for AFP (b), SALL4 (inset: negative control) (c), and arginase-1 (d), focally for CDX2 (e) and PDX1 (inset: negative control) (f). An intramucosal transition between the hepatoid and conventional component was seen $(\mathbf{g}, \mathbf{h})$. AFP, alpha-fetoprotein. 


\section{Case Reports in Gastroenterology}

Case Rep Gastroenterol 2020;14:426-435
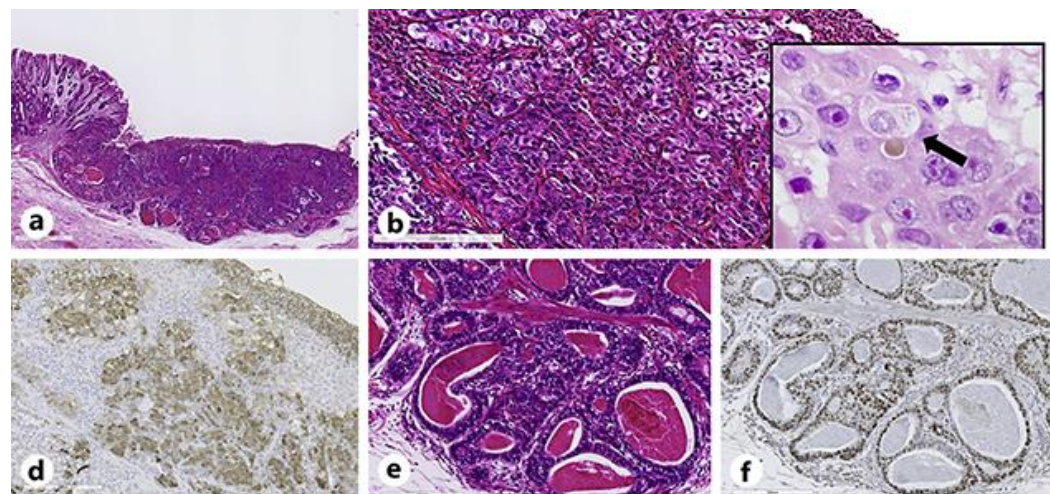

DOI: $10.1159 / 000508413$

(C) 2020 The Author(s). Published by S. Karger AG, Basel

Iwaya et al.: Early Gastric Cancer with Intramucosal Hepatoid Morphology
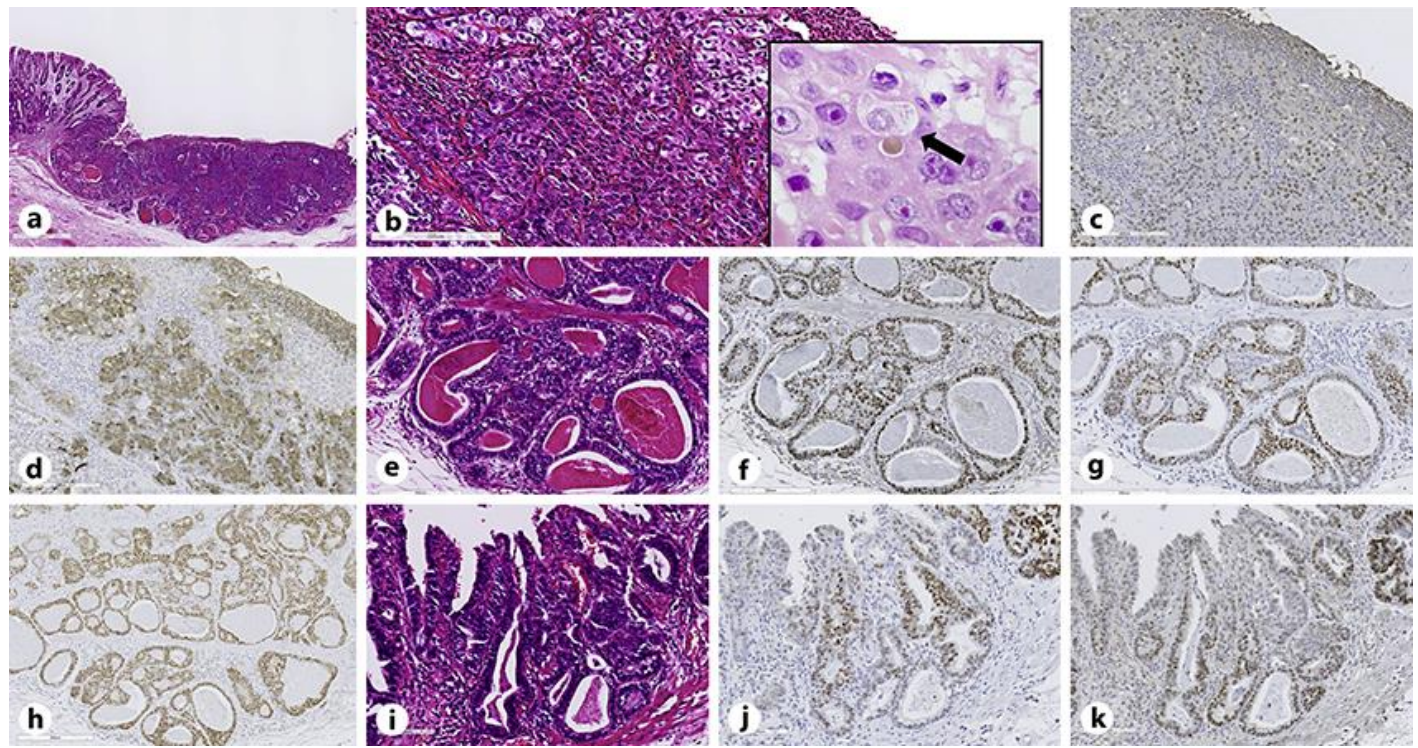

Fig. 3. Case 2 showed a slightly depressed lesion (a) and hepatoid component (b) showed bile production (inset) with SALL4 (c) and arginase-1 (d) expression. Fetal enteric component showed glandular structure with clear cytoplasm (e) and immunoreactivity for SALL4 (f), CDX2 (g), and PDX1 (h). Intramucosal conventional-type component (i) showed focal CDX2 expression (j) and SALL4 expression (k).
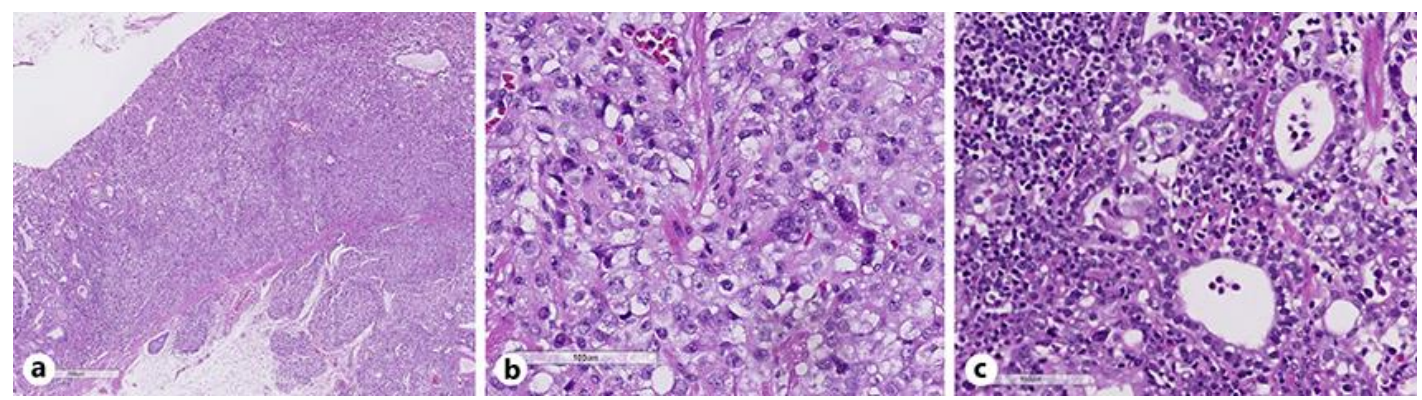

Fig. 4. Case 3 showed an intramucosal-submucosal solid lesion (a) with hepatoid (b) and fetal enteric morphology (c). 
Case Reports in Gastroenterology
Case Rep Gastroenterol 2020;14:426-435

(c) 2020 The Author(s). Published by S. Karger AG, Basel www.karger.com/crg

Iwaya et al.: Early Gastric Cancer with Intramucosal Hepatoid Morphology

Table 1. Immunohistochemical expression patterns observed in each component (cases 1-3)

\begin{tabular}{llll}
\hline Antigen & Hepatoid component & Fetal enteric component & $\begin{array}{l}\text { Conventional-type } \\
\text { component }\end{array}$ \\
\hline SALL4 & $(+++) /(+++) /(+++)$ & $\mathrm{ND} /(+++) /(+++)$ & $0 /(+) /(+)$ \\
AFP & $(++) /(+++) /(+++)$ & $\mathrm{ND} /(+++) /(+++)$ & $0 / 0 / 0$ \\
Arginase-1 & $(+++) /(+++) /(+++)$ & $\mathrm{ND} / 0 / 0$ & $0 / 0 / 0$ \\
HepPar1 & $(+++) /(+++) /(+++)$ & $\mathrm{ND} /(+) /(+)$ & $0 /(+) /(+++)$ \\
CDX2 & $(+) /(+) /(++)$ & $\mathrm{ND} /(+++) /(++)$ & $0 /(+++) /(+++)$ \\
PDX1 & $(+) /(++) /(+)$ & $\mathrm{ND} /(+++) /(++)$ & $(+++) /(+++) /(+++)$ \\
MUC2 & $0 / 0 / 0$ & $\mathrm{ND} /(+) / 0$ & $0 /(+) /(++)$ \\
MUC5AC & $0 / 0 / 0$ & $\mathrm{ND} / 0 / 0$ & $(+) /(+) /(+++)$ \\
MUC6 & $0 / 0 / 0$ & $\mathrm{ND} / 0 / 0$ & $(+) /(+) /(++)$ \\
\hline
\end{tabular}

The extent of immunostaining was scored as follows: (i) 0 , negative, no positive cells; (ii) + , focal expression, less than one-third of cells were positive; (iii) ++ , one-third to two-thirds were positive; and (iv) +++ , diffuse expression, more than two-thirds of the cells were positive. AFP, alpha-fetoprotein; ND, not detected. 